\title{
EXPERIMENTAL STUDY OF HOLE CLEANING PERFORMANCE OF UNDERBALANCED DRILLING AT DOWNHOLE CONDITIONS
}

\author{
Y. B. Adeboye ${ }^{1}$ and L. 0. Oyekunle ${ }^{2}$ \\ 1,2 DEPARTMENT OF ChEMICAL ENGINEERING, UNIVERSITY OF LAGOS, AKOKA, LAGoS STATE, NIGERIA \\ E-mail addresses: ${ }^{1}$ yadeboye@unilag.edu.ng, 2 loyekunle@unilag.edu.ng
}

\begin{abstract}
Underbalanced drilling is one of the most widely used drilling technologies while drilling poor permeability, low pressure and depleted reservoirs. Advantages inherent in application of this drilling technique which are major factors affecting cost, time and drilling quality can be significantly hindered due to poor hole cleaning performance. Experimental study of hole cleaning performance in underbalanced drilling at downhole temperatures $26^{\circ} \mathrm{C}, 40^{\circ} \mathrm{C}$ and $600^{\circ} \mathrm{C}$ and water influx of $0.25 \mathrm{~m}^{3} / \mathrm{s}$ in a simulated vertical well using gasified mud was carried out. Results showed that increasing down-hole temperature by $34^{\circ} \mathrm{C}$ above $26^{\circ} \mathrm{C}$ (ambient temperature) caused $42 \%$ and $21.6 \%$ increase in annular concentration at flow rates $0.3 \mathrm{~m}^{3} / \mathrm{s}$ and $1.6 \mathrm{~m}^{3} / \mathrm{s}$ respectively. Increasing mud flow rate by $1.3 \mathrm{~m}^{3} / \mathrm{s}$ above $0.3 \mathrm{~m}^{3} / \mathrm{s}$ at downhole temperatures: $26^{\circ} \mathrm{C}$ and $60^{\circ} \mathrm{C}$ and water influx at $0.25 \mathrm{~m}^{3} / \mathrm{s}$ caused $68 \%$ and 47.6\% decrease in annular cutting concentration. Increase in downhole temperature at constant flow rate resulted in poor hole cleaning performance due to increased in annular cutting concentration. Also, increasing mud circulation rate at a given downhole temperature led to an improved hole cleaning performance due to decrease in annular cutting concentration. Sensitivity studies of effect of mud viscosity, gas/liquid ratio, cutting density and water influx at $40^{\circ} \mathrm{C}$ revealed that increasing mud viscosity and gas/liquid ratio significantly improved the hole cleaning performance while cutting density and water influx cause poor hole cleaning. However, effect of increasing water influx becomes problematic only when the volume is excessively high and miscible with the circulating mud.
\end{abstract}

Keywords: Hole Cleaning performance, underbalanced drilling, downhole conditions, cutting concentration and gasified mud.

\section{INTRODUCTION}

Effective cuttings removal from the bottom of the wellbore is essential to minimize energy which will be dissipated at the bit, and maximize the hydraulic power that will be used to increase the penetration rate in medium to hard formation as drilling progresses. This implies that inadequate hole cleaning affect the economy of overall drilling optimization process. Thus, in order to achieve drilling cost reduction, improvement in drilling technologies for the development of vertical, directional and horizontal wells is imperative.

Poor hole cleaning which often occurs in the highly deviated sections and horizontal sections of the complex structural wells [1] could be attributed to decrease in cutting carrying capacity of the drilling fluid. Hole cleaning is one of the major factors affecting cost, time and quality of vertical, directional and horizontal well [4]. Inadequate hole cleaning can result in expensive drilling problems such as pipe sticking, premature bit wear, slow drilling, formation fracturing and high torque and drag. [3, 6, 9].

Ozbayoglu et al. [5] performed extensive experiments to analyze the effects of major parameters such as flow rate, inclination and critical velocity on cuttings transport efficiency in (LPAT) flow-loop. The results showed that average annular velocity is the dominating parameter that influence hole cleaning . However, cuttings properties, fluid density, inclination and eccentricity also have some effects on cuttings transport. Zhou [11] carried out experiments where effects of liquid and gas flow rates on cuttings transport were investigated under elevated pressure and elevated temperature (EPET). The results showed that liquid flow rate, gas-liquid ratio and temperature essentially affect cutting transport efficiency and frictional pressure drop.

\footnotetext{
* Corresponding author, Tel: +234-813-369-2373
} 


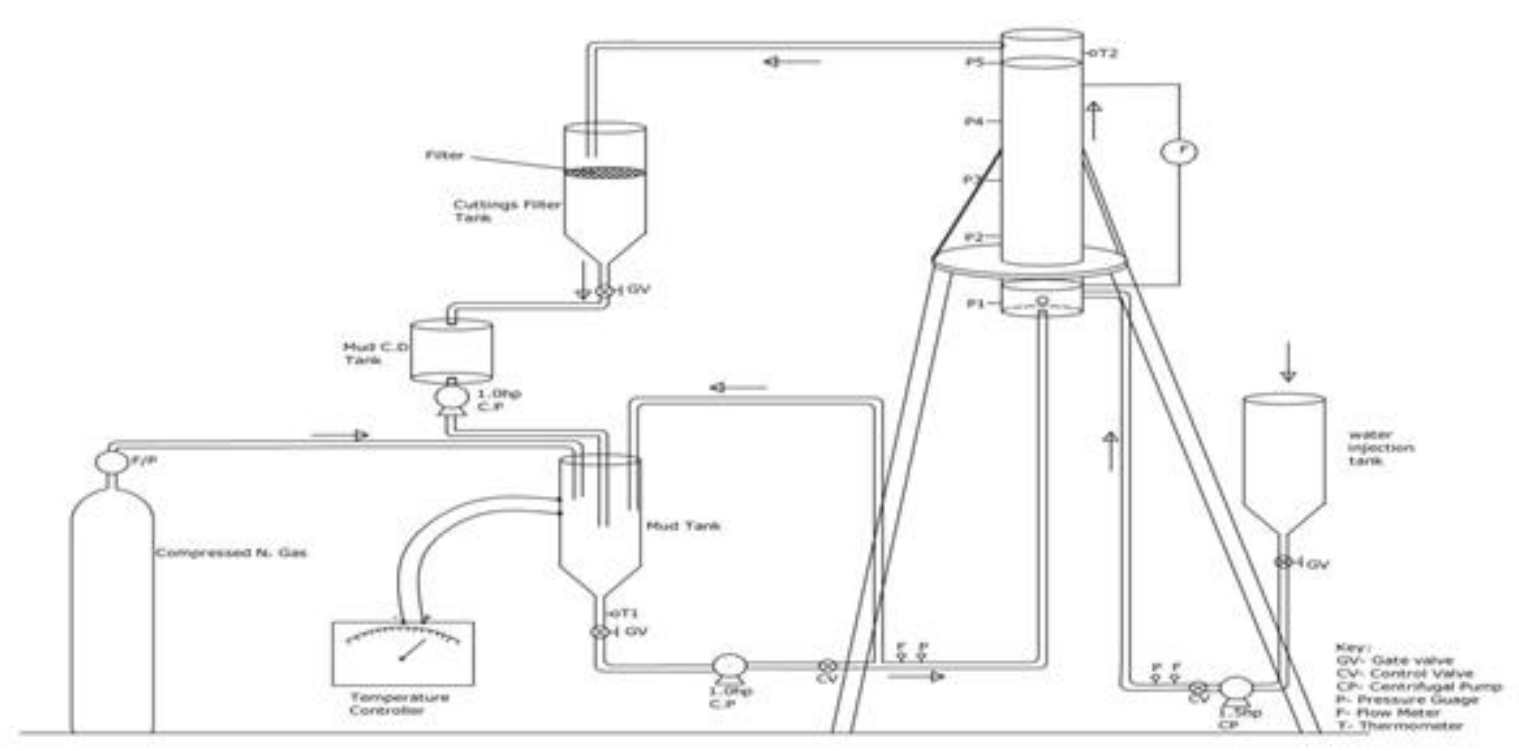

Fig 1: Schematic Diagram of a Close Flow loop

The effectiveness of using fiber sweep for hole cleaning and reduction of cutting bed thickness in horizontal and highly deviated sections was recently considered [1, 2, 10]. Valluri et al. [10] investigated the effect of rheology of the sweep fluid on sweep efficiency under LPAT and EPET conditions. It was reported that, in the absence of drill pipe rotation, high viscosity and high density sweeps were found to be ineffective in a horizontal configuration and temperature affects the sweep efficiency by changing the rheological properties of drilling fluid. Ahmed and Takach [1] conducted hole cleaning performance of a fiber sweep and discovered that the Xanthum gum mixed with synthetic fiber has better hole cleaning capacity than when mixed with base fluid in horizontal well configuration. Similarly, Cheung et al. [2] conducted experiments with drillpipe rotation speeds (0 - $90 \mathrm{rpm})$ and different fiber concentrations. It was reported that an increase in fiber concentration improved the hole cleaning efficiency with high pipe rotation or flow rate.

Sun et al. [8] carried out review of research works in hole cleaning in complex structural wells on the effects of flow rate, inclination, mud rheology, drillpipe rotation and other factors on hole cleaning and some correlations and models were developed. The major areas identified as gab for future experimental research study is the use of flow loop that depicts the real cuttings transport under downhole conditions including formation fluid influx, wellbore collapse and the annular temperature.

Zhou et al. [2] and Valluri et al. [6] carried out experimental study of cuttings transport under elevated pressure and elevated temperature (EPET) which also epitomized downhole conditions. The validity and applicability of their findings are restricted to overbalanced drilling only. Hole cleaning performance is used as indicator to quantitatively determine the effect of down hole temperature condition on cutting carrying capacities of gasified drilling fluid in underbalanced drilling.

\section{EXPERIMENTAL SET UP}

The flow loop (Figure 1) consists of a vertically oriented $45 \mathrm{~cm}$ long stainless steel with diameter $9.56 \mathrm{~cm}$ and $3.2 \mathrm{~cm}$ as outer and inner pipes and lagged right from the mud and formation water influx flow-lines. The flanges, one on each side of the column, were also built to hold it firmly and keep it vertically. Mounted on the body are the pressure gauges, thermometers and a liquid flow meter to measure the annular fluid pressure, temperature and flow rates during fluid circulation respectively. Observations were on $36 \mathrm{~cm}$ "Test Section" of the annulus where the circulating fluid is not influenced by entrance and exit effects in the annulus.

There are four tanks, each with storage capacity of 50litres and two tanks (A and B) are meant for mud tank and desander, the tank $C$ is for water injection to simulate water formation influx during underbalanced drilling while tank $\mathrm{D}$ is mud pit for mud conditioning. In mud tank, the entire body is covered with heating element connected to temperature control system with thermostat to simulate down-hole temperature condition. Also, Thermometer $\mathrm{T}_{1}$ is fixed on the mud flow line to measure mud temperature. However, 
beads having diameter $1.42 \mathrm{~mm}$ were used as simulated cuttings and cuttings concentration of $34.5 \%(\mathrm{w} / \mathrm{w})$ (which is $1.54 \mathrm{Kg}$ equivalent by weight) were loaded into the annulus at the bottom before circulation. Mud circulation and water injection were established using $1.0 \mathrm{Hp}$ and $1.5 \mathrm{Hp}$ centrifugal pumps respectively and control valves which help to adjust the flow to the desired flow/injection rateliquid flow meter $(F)$ is installed in each flowline to measure mud injection and water influx rates.

\section{METHODOLOGY}

Experimental run was initiated by preparing circulating mud in a mud pit. This was achieved by mixing known weight of bentonite with 50litres of water. Also, carboxyl-methyl cellulose(CMC) polymer was added as viscosifying agent to produce the desired viscosity while sodium chloride $(\mathrm{NaCl})$ was also added to correct the $\mathrm{pH}$ and to prevent clay swelling (i.e. bentonite). $\mathrm{pH}$, density, and viscosity of the drilling fluid were measured with JENWAY $\mathrm{pH}$ meter, mud balance, marsh funnel viscometer respectively. The mud was properly mixed until homogeneous solution was obtained, it was then pumped with $1.0 \mathrm{hp}$ centrifugal pump to a mud tank connected to temperature controlling system shown Figure 1 The temperature controlling system was set on and heating element began to heat the mud tank and its content until desired mud temperature value was attained. Then, mud circulation was initiated by opening the gate valve, putting on 1.0hp centrifugal pump and simultaneously opening the control valve respectively. Similarly, formation water having the same temperature as injected mud was influx by opening the gate valve and putting on $1.5 \mathrm{hp}$ centrifugal pump on the flow-line connected to wellbore at the base. Prior to mud circulation, wellbore was loaded with $1.54 \mathrm{Kg}$ of cuttings. Appropriate readings such as flow rate and mud temperature were made for each circulation when steady flow conditions were attained and the procedure was repeated three times. The cutting concentration was determined by weighing filtered cuttings at the surface and deducted from the amount loaded into the wellbore. This procedure was carried out for each mud flow rate. The flow rate was increased in steps of $0.20 \mathrm{~m}^{3} / \mathrm{s}$ and appropriate readings taken at each step were repeated three times. The mud flow rate was increased stepwise; water influx, mud temperature and gas injection flow rates were kept constant.
Experiments were carried out at ambient temperature $\left(26^{\circ} \mathrm{C}\right)$ and continued until $60^{\circ} \mathrm{C}$ at interval of $5^{\circ} \mathrm{C}$. Sensitivity studies were carried out at $40^{\circ} \mathrm{C}$ to investigate effects of change in operating parameters such as mud viscosity, cutting density, gas/liquid ratio (GOR) and water influx on hole cleaning performance.

\section{RESULTS AND DISCUSSION}

\subsection{Hole Cleaning Performance}

The impact of down-hole temperature on cutting carrying capacities of water-based gasified mud is quantitatively measured in this study using hole cleaning performance at different down-hole temperatures in underbalanced drilling as indicating parameter. It is shown in Figure 2 that at constant temperature, annulus cutting concentration profile decreases with increase in mud flow rate. Specifically, As shown in Table 1, increasing flow rate by $1.3 \mathrm{~m}^{3} / \mathrm{s}$ above flow rate of $0.3 \mathrm{~m}^{3} / \mathrm{s}$ caused decrease of $47.6 \%$, $65 \%$ and $68 \%$ at down-hole temperatures of $26^{\circ} \mathrm{C}$, $40^{\circ} \mathrm{C}$ and $60^{\circ} \mathrm{C}$ respectively. Also, at constant flow rate, increase in downhole temperature causes increase in annular cutting concentration. This can be corroborated using Table 2 where an increase of $34^{\circ} \mathrm{C}$ above ambient temperature $\left(26^{\circ} \mathrm{C}\right)$ caused increase of $42 \%$ and $21.6 \%$ in annular cutting concentration at flow rate of $0.3 \mathrm{~m}^{3} / \mathrm{s}$ and $1.6 \mathrm{~m}^{3} / \mathrm{s}$ respectively. The result shows that annulus cutting concentration profile decreases as mud flow rate increases. Conclusively, the result shows, that although increase in down-hole temperature causes increase in annular cutting concentration at constant flow rate, the flow regime significantly determines the amount of annular cutting concentration deposited at a particular temperature. The higher the flow rate, the lower the amount of cuttings deposited at a given temperature. Thus, the effect of flow regime supersedes the effect of down-hole temperature at turbulent flow condition. This is due to the fact that at turbulent flow condition, friction is reduced. Hence, annular velocity increased and thereby increased the amount of cuttings suspended and improved hole cleaning. Hence, increase in mud flow rate increases hole cleaning performance in underbalanced drilling. The study has shown that increase in down-hole temperature causes poor hole cleaning performance at constant mud flow rate. Thus, it is imperative that mud flow-rate that will provide efficient hole cleaning must be determined during operations design for respective 
down-hole temperature conditions in order to guarantee drilling success

\subsection{Effect of Water influx}

In underbalanced drilling, wellbore pressure due to circulation of underbalanced fluid system (air, gas, foam, aerated water or gasified mud) is always lower than formation pressure to allow influx of formation (gas, oil or water) in drilling practice. The effect of water influx on hole cleaning performance in underbalanced drilling with gasified mud at downhole temperature $40^{\circ} \mathrm{C}$ was investigated. It is shown in Figure 3 that at constant water influx, annulus cutting concentration profile decreases with flow rate and almost similar trend occurred even when there was no water influx. The result showed that increase in mud flow rate or flow regime caused decrease in annulus cutting concentration whether there is water influx or not. However, at high flow rate, increase in water influx causes increase in annulus cutting concentration. This finding could be attributed to high degree of dilution as water influx increases particularly when formation influx is compatible with circulating mud. Thus, viscosity which determines carrying capacity of the injected mud decreases as water influx increases. it was also observed that degree of circulating mud dilution also play significant role. This is reflected in Figure 3 as there was no appreciable change in cutting concentration when water influx at $0.25 \mathrm{~m}^{3} / \mathrm{s}$ and when there was no water influx until the volume of formation influx significantly increased. The result has shown that although increase in water influx causes poor hole cleaning. However, the effect becomes problematic only when the volume is excessively high and influx formation is miscible with the circulating mud.

\subsection{Effect of Mud Viscosity}

Hole cleaning performance shown in Figure 4 revealed that annular cutting concentration profile decreases as mud flow rate increases at constant viscosity. This observation could be attributed to increase in bottom-hole pressure due to turbulent flow condition at high flow rate. Thus, the amount of cuttings deposition at the bottom of the annulus would be greatly reduced. Also, increase in mud viscosity reduces annulus cutting concentration. The results showed that increase in mud viscosity causes decrease in annulus cutting concentration. Decrease in annulus cutting concentration owing to increase in mud viscosity could be attributed to increase in lifting capacity of drilling fluid as mud viscosity increased and thereby improved hole cleaning. Although there is no significant difference in hole cleaning performance as mud is circulated whether at low or high flow rate as mud viscosity increases, poor hole cleaning occurred when injected mud flow rate was $0.3 \mathrm{~m}^{3} / \mathrm{s}$ while efficient hole cleaning occurred at high flow rate. Hence, this shows that increase in mud viscosity of circulating fluid in underbalanced drilling provides better hole cleaning performance but improvement in hole cleaning performance is independent of injected mud flow rate. Also, the result shows that there was annular cutting concentration of $10 \%$ which depicts efficient hole cleaning performance of mud having appropriate viscosity of $43.1 \mathrm{cp}$ was injected at flow rate $1.6 \mathrm{~m}^{3} / \mathrm{s}$ and down-hole temperature $40^{\circ} \mathrm{C}$. The study has shown that it is imperative that during underbalanced drilling, for a given down-hole temperature, circulating fluid should have appropriate viscosity and must be circulated at very high flow rate to ensure efficient hole cleaning performance.

\subsection{Effect of Gas/Liquid Ratio (GOR)}

It is shown in Figure 5 that at constant GOR, increase in mud flow rate causes decrease in annulus cutting concentration. The scenario could be attributed to reduction in frictional effect as gas flow rate increases. Also, the annulus cutting concentration profile decreases steadily as GOR increases. This finding is in agreement with Oudeman's work [7] which stated that adding $10 \mathrm{vol} . \%$ to $20 \mathrm{vol} \%$ of gas to mud increases sand transport greatly. The critical analysis of the result revealed that although annulus cutting concentration profile decreases as GOR which epitomizes gas volume increases, greater change occurred when GOR was between $0.3-8.0$ for only $0.27 \mathrm{~m}^{3} / \mathrm{s}$ and $0.57 \mathrm{~m}^{3} / \mathrm{s}$. The result is in agreement with Leising and Waiton [8] that there exists increase in turbulence by the presence of limited amount of gas and helps the solids in suspense. Thus, the greater increase in hole cleaning performance between GOR $0.3-8$ can be attributed to limited amount of gas volume which primarily increase turbulence and expansion as it near the surface, annular velocity simultaneously increased. it could be concluded that achieving improvement in hole cleaning performance in underbalanced drilling with gasified mud, is not just adding certain $\%$ volume of gas to mud as revealed by Oudeman's study [7], the mud volumetric flow rate also plays very significant role. 

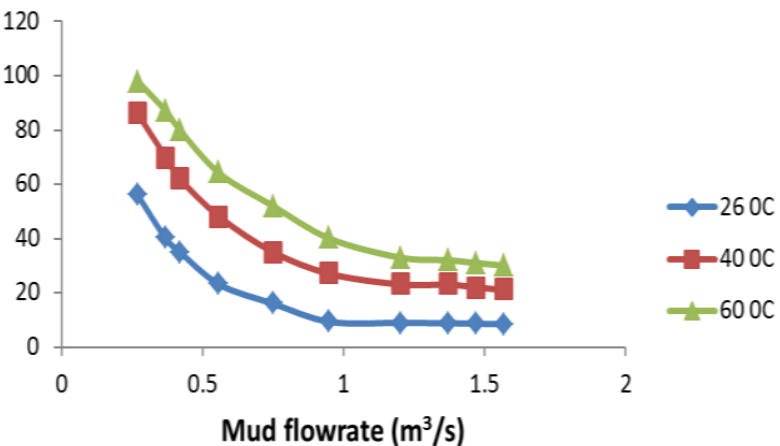

Figure 2: Cutting concentration profile with Mud Temperature

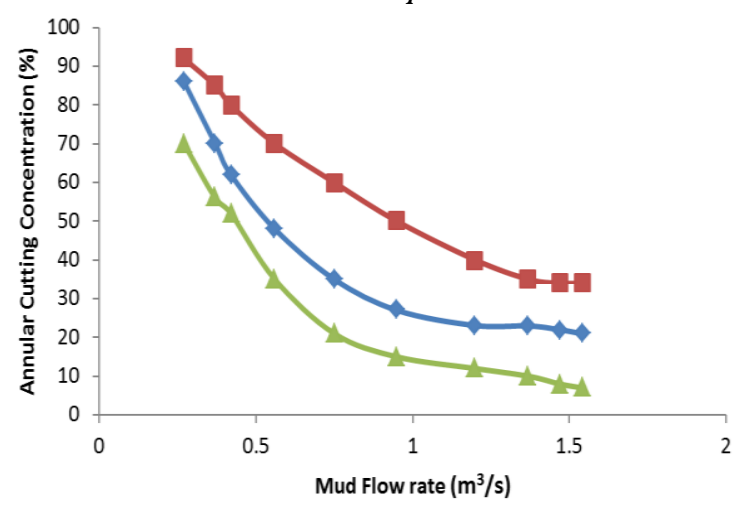

Figure 4: Cutting concentration profile at different mud viscosity

Table 1: Annular Cutting Concentration \% at Different Downhole Temperatures

\begin{tabular}{cccc}
\hline \multirow{2}{*}{ Flow rate $\mathrm{m}^{3} / \mathrm{s}$} & \multicolumn{3}{c}{ Cutting Conc. $\%$} \\
\cline { 2 - 4 } & $26^{0} \mathrm{C}$ & $40^{\circ} \mathrm{C}$ & $60^{\circ} \mathrm{C}$ \\
\hline 0.3 & 56 & 86 & 98 \\
1.6 & 8.4 & 21 & 30 \\
\hline
\end{tabular}

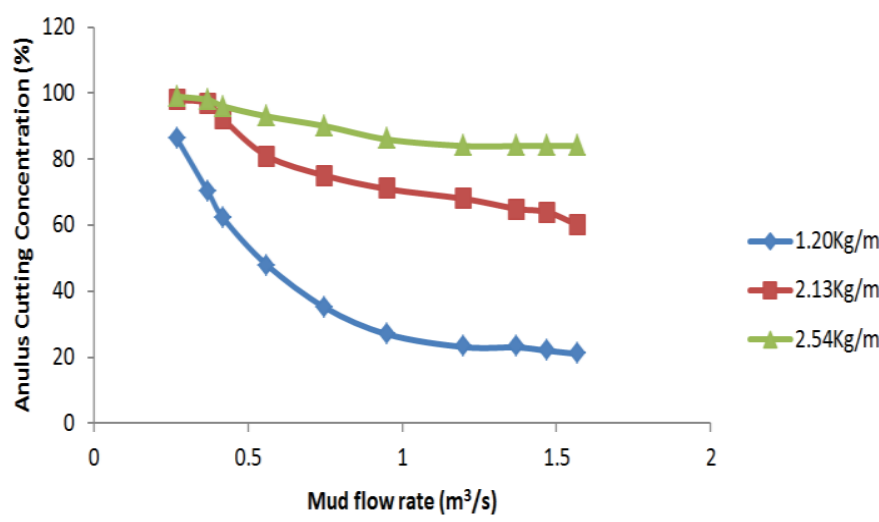

Figure 6: Cutting concentration profile due to different cutting density

\subsection{Effect of Cutting Density}

Figure 6 shows the annulus cutting concentration profile due to transportation of cutting having various densities. Higher cutting density means higher gravitational contribution, thus, for efficient hole

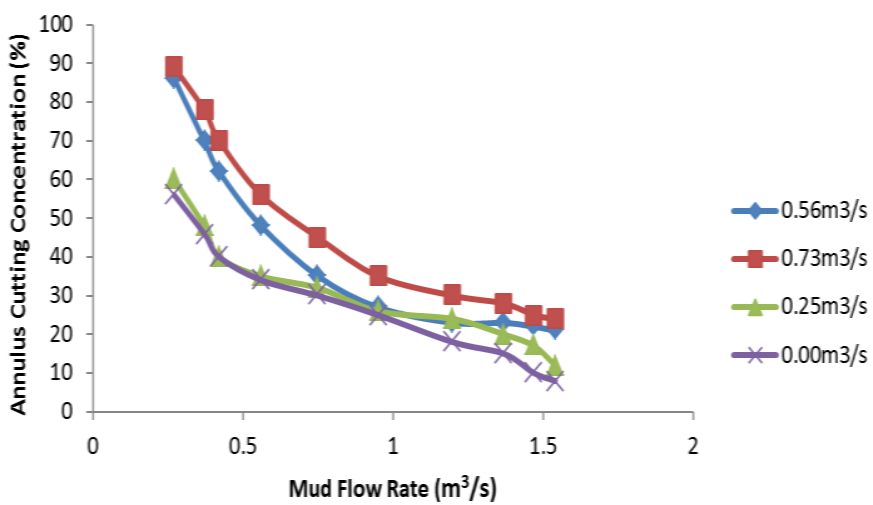

Figure 3: Cutting concentration profile for various water influx at downhole temperature $40^{\circ} \mathrm{C}$

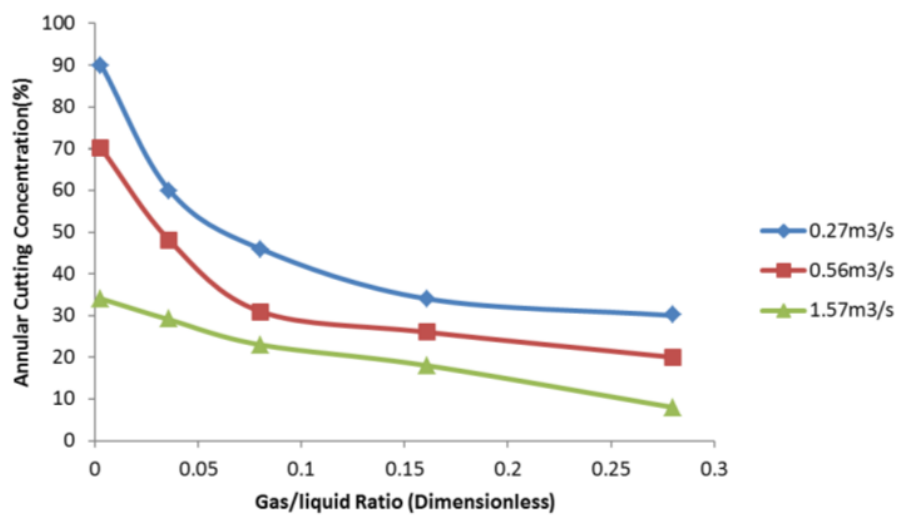

Figure 5: Cutting concentration profile at different gas/liquid ratio

cleaning to be achieved, the cumulative effect of buoyancy and lifting forces provided by the circulating mud must be higher than the gravitational effect due to cutting transport. Figure 6 shows steady decrease in annulus cutting concentration as flow rate increases for mud transporting cuttings having density $1.20 \mathrm{~kg} / \mathrm{m}^{3}$. Also, there is no significant decrease in annulus cutting concentration due to transportation of cuttings having densities $2.13 \mathrm{~kg} / \mathrm{m}^{3}$ and $2.54 \mathrm{~kg} / \mathrm{m}^{3}$ despite increase in mud flow rate. The obtained result shows that, comparatively, hole cleaning performance is most efficient when transporting cutting having density $1.20 \mathrm{~kg} / \mathrm{m}^{3}$. This is due to the fact that an increase of $1.30 \mathrm{~m}^{3} / \mathrm{s}$ in mud injected flow rate caused $65 \%, 38 \%$ and $15 \%$ decrease in annulus cutting concentration. The result shows that significant improvement occurs when flow rate is increased with transport cutting with density of $1.20 \mathrm{Kg} / \mathrm{m}^{3}$. This indicates that there is need to inject mud at flow-rate higher than $1.6 \mathrm{~m}^{3} / \mathrm{s}$ to provide better hole cleaning performance. However, it was observed that increase in cutting density at constant flow rate causes decrease in hole cleaning performance. 


\section{CONCLUSIONS}

Experimental study of hole cleaning performance in underbalanced drilling using gasified mud as circulation fluid system was carried out. The following conclusions can be made:

Increase in mud injected flow rate five times above $0.3 \mathrm{~m}^{3} / \mathrm{s}$ at mud temperature $26^{\circ} \mathrm{C}$ and $60^{\circ} \mathrm{C}$ caused $68 \%$ and $47.6 \%$ decrease in annular cutting concentration showing better hole cleaning performance in underbalanced drilling. Increase in down-hole temperature by $34^{\circ} \mathrm{C}$ above $26^{\circ} \mathrm{C}$ at constant flow rates $0.3 \mathrm{~m}^{3} / \mathrm{s}$ and $1.6 \mathrm{~m}^{3} / \mathrm{s}$ respectively resulted in $42 \%$ and $21.6 \%$ increase in annular cutting concentration showing poor hole cleaning performance.

Water influx significantly influence hole cleaning performance only when volume is excessively high with minimum influx rate $0.25 \mathrm{~m}^{3} / \mathrm{s}$ and besides, influx formation must be miscible with the circulating mud. Increasing viscosity of circulating mud by $81.5 \%$ and also, cutting density by $100 \%$ resulted in $27 \%$ decrease in annular cutting concentration and 63\% increase in annular cutting concentration respectively at circulating mud flow rate $1.6 \mathrm{~m}^{3} / \mathrm{s}$. This shows that increase in mud viscosity causes improved hole cleaning performance while cutting density increase results in poor hole cleaning performance

Achieving improvement in hole cleaning performance in underbalanced drilling with gasified mud, is not just increasing volume of gas contained in gasified mud, the volumetric flow rate of injected gasified mud must increase simultaneously.

\section{NOMENCLATURE}

LPAT: Low Pressure, Ambient Temperature

EPET: Elevated Pressure, Elevated Temperature

LPET : Low Pressure, Elevated Temperature

A : Mud Tank

B : Desander

C : Water Injection Tank

D : Mud C.D. Tank

GV : Gate Valve

CV : Control Valve

$\mathrm{CP} \quad$ : Centrifugal Pump

$P \quad$ : Pressure Gauge

F : Flow meter

$\mathrm{T} \quad$ : Thermometer

\section{ACKNOWLEDGEMENT}

The authors wish to gratefully acknowledge the support of University of Lagos for financing this project through Tetfund Research Grant CRC/Tetfund/No.2011/07.

\section{REFERENCES}

[1] Ahmed R.M., and Takach N.E. "Fiber sweeps for hole cleaning". SPE Drilling \& Completion, Vol. 24, pp. 564572. 2009

[2] Cheung, E., Takachi, N., Ozbayoglu, E., Majidi, R., Bloys, B. "Improvement of Hole Cleaning Through Fiber Sweeps".SPE Deepwater Drilling and Completions Conference, pp. 1-1, 2012.

[3] Ford J.T., Peden J.M., Oyeneyin E.G. and Zarough R. “ Experimental Investigation of Drilled Cuttings Transport in Inclined Borehole", SPE 20421, presented at the $65^{\text {th }}$ Annual Technical Conference, New Orleans Louisiana, 1990.

[4] Mishira, N. "Investigation of Hole Cleaning Parameters Using computational Fluid dynamics in Horizontal and Deviated Wells" , M.S. Thesis, West Virginia University, West Virginia, USA, 2007.

[5] Ozbayoglu, M.E., Stefan , Z.M., Troy Reed and Tabach, N. "Analysis of the Effects of Major Drilling Parameters on Cuttings Transport Efficiency for High Angle Wells in Coiled Tubing Drilling Operations", SPE/ICOTA Coiled tubing Conference and exhibition, pp. 1-1, 2004.

[6] Pilevhavari, A.A. Azar, J.J., Shiraz, S.A. "State -of-theArt Cuttings Transport in Horizontal Wellbores", SPE Drilling \& Completion, Vol. 14, pp. 196 -200, 1999.

[7] Qudeman, P. "Sand Transport and Deposition in Horizontal Multiphase Trunklines of Subsea Satellite Developments", SPEPF (November, 1993), 237, 1993.

[8] Sun Xiaofeng, Wang Kelin, Yan Tie, Zhang Yang, Shao Shuai, Luan Shizhu"Review of Hole Cleaning in Complex Structural Wells", Open Petroleum Engineering Journal, Vol. 6, pp. 25 -32, 2013.

[9] Tomren, P.H., Iyoho, A.W., Azar J.J. "An Experimental Study of Cuttings Transport in Directional Wells", SPE Drilling Engineering, pp. 43 - 56, 1986.

[10] Valluri, S.G. ,Miska, S.Z., Ahmed R., Yu, M., Takach, N.E. "Experimental Study of Effective Hole Cleaning Using Sweeps in Horizontal Wellbores", SPE Annual Technical Conference and Exhibition, pp.1 -13, 2006.

[11] Zhou L. "Hole Cleaning During Underbalanced Drilling in Horizontal and Inclined Wellbore", SPE Drilling \& Completion Journal, Volume 23, Number 3, $267-27,2008$. 